\title{
ENSINO PÚBLICO SUPERIOR E EXCLUSÃO ÉTNICA E RACIAL
}

\section{Ari Lima ${ }^{1}$}

Resumo: Este artigo pretende tecer algumas considerações acerca de que modo a ênfase sobre as questões racismo, preconceito, discriminação e desigualdade racial favorecem a percepção da diferença étnica e racial em sala de aula, assim como favorecem a compreensão da importância do desenvolvimento de práticas didático-pedagógicas que valorizem as alteridades socialmente excluídas e o desenvolvimento de mecanismos de inclusão racial e étnica, particularmente, no ensino superior. Neste sentido, tomam-se como referências um trabalho de avaliação de projetos de acesso e permanência de estudantes negros e carentes ao ensino superior e um seminário ministrado em curso de formação para professores do ensino fundamental e médio na UNEB.

Palavras-Chave: Ensino superior; Aluno; Professor; Exclusão.

Abstract: This work aims to make some reflections of how the emphasis on some topics as racism, prejudice, discrimination and racial desiguality benefits the perception of ethnic and racial difference in classroom as well as the comprehension of importance to develop didactical and pedagogical practices which value the socially-excluded alterity and so mechanisms of racial and ethnic inclusion chiefly in University Education. Like this a work of evaluation based on access project and the black and poor student remaining in University as well as a seminar held in a training course to elementary and high school teachers at UNEB are taken as a reference to this paper.

Key Words: University Education; Student; Teacher; Exclusion.

\section{INTRODUÇÃO}

No primeiro semestre do ano de 2003, participei como consultor de um trabalho de avaliação de projetos que pretendiam assegurar o acesso e permanência de estudantes negros e carentes em universidades públicas. Tais projetos eram financiados pelo Programa Políticas da Cor (PPCor) na Educação Brasileira, implementado pelo Laboratório de Políticas Públicas LPP - da Universidade do Estado do Rio de Janeiro (UERJ). Mais tarde, em

1 Nome completo cadastrado na Plataforma Lattes: Arivaldo de Lima Alves; Doutorado em Antropologia Social pela Universidade de Brasília (UnB); Professor Adjunto da Universidade do Estado da Bahia (UNEB), Campus II, Alagoinhas; Professor Permanente do Programa de Pós-Graduação em Crítica Cultural (Pós-Crítica/UNEB II); Líder de Grupo de Pesquisa cadastrado no CNPq: Núcleo das Tradições Orais e Patrimônio Imaterial (NUTOPIA). Endereço eletrônico: arilima.2004@uol.com.br. 
março de 2006, participei do Programa de Formação de Professores (PROESP/UNEB) para o ensino fundamental e médio, quando ministrei um seminário de $15 \mathrm{~h}$ - "A temática negra e as relações raciais no Brasil" -, nas dependências do Campus II da UNEB. A partir destas duas experiências, pretendo neste artigo tecer algumas considerações sobre de que modo a ênfase sobre as questões racismo, preconceito, discriminação e desigualdade racial favorecem a percepção da diferença étnica e racial em sala de aula e, conseqüentemente, a compreensão da importância do desenvolvimento de práticas didático-pedagógicas que valorizem as alteridades socialmente excluídas e o desenvolvimento de mecanismos de inclusão racial e étnica, particularmente, no ensino superior. A propósito, Mariléia dos Santos Cruz (2005) observa que a História da Educação Brasileira tem se configurado como a história da escolarização de camadas médias da população. Isto quer dizer que

\begin{abstract}
[...] têm sido esquecidos os temas e as fontes históricas que poderiam nos ensinar sobre as experiências educativas, escolares ou não, dos indígenas e dos afro-brasileiros. O estudo, por exemplo, da conquista da alfabetização por esse grupo; dos detalhes sobre a exclusão desses setores das instituições escolares oficiais; dos mecanismos criados para alcançar a escolarização oficial; da educação nos quilombos; da criação de escolas alternativas; da emergência de uma classe média negra escolarizada no Brasil; ou das vivências escolares nas primeiras escolas oficiais que aceitaram negros são temas que, além de terem sido desconsiderados nos relatos da história oficial da educação, estão sujeitos ao desaparecimento (CRUZ, 2005, p. 22).
\end{abstract}

Embora levante questões, interprete e analise dados, privilegio a descrição e narração destas duas experiências supracitadas com o intuito de registrar e expor à reflexão pública contextos periféricos do sistema de ensino no Brasil. O trabalho de avaliação de alguns projetos do PPCor, de fato, se iniciou com o encontro realizado entre consultores e a coordenação do Programa em julho de 2003, na cidade do Rio de Janeiro. Tal encontro, do mesmo modo que nos preparou tecnicamente para avaliar os projetos financiados, nos inseriu no contexto político-pedagógico do PPCor, qual seja a elaboração e execução de modelos pedagógicos que preparassem os jovens para o ingresso e/ou permanência na universidade, através de uma política da cor que deveria fortalecê-los intelectualmente, assim como psicológica e emocionalmente através da positivação da descendência negra. Em seguida, visitei e avaliei quatro projetos: o Projeto Tutoria, em Salvador - BA; o Projeto Pré-Universitário para Negros e Excluídos (PRUNE), em 
Itabuna - BA; o Projeto Auta de Souza, em Olinda - PE; o Projeto Casa do Padre Melotto, em Olinda - PE.

Em todos os casos, ouvi reclamações sobre a escassez e retardamento no repasse de recursos e sobre um precário trânsito de informações entre os coordenadores dos projetos e a coordenação do PPCor. Por outro lado, constatei que a maioria dos projetos, na medida em que pretendiam atacar certas demandas, o faziam despertando outras que, acredito, projetos deste porte não são capazes de resolver, uma vez que estas demandas deveriam ser atribuições de um Estado de Bem Estar constituído e autodefinido como plenamente democrático e universalista. Aponto, portanto, para as dificuldades do PPCor, como agente financiador e coordenador político-pedagógico, assim como para os acertos, limites e equívocos dos projetos financiados no que diz respeito a um equilíbrio entre objetivos previamente indicados e a expectativa de reversão de desigualdades sociais e adequação entre programa pedagógico e uma política da cor.

Em relação ao seminário que ministrei para os professores do PROESP/UNEB, novamente as precárias condições de trabalho dificultaram a construção do problema em pauta e a exploração de alternativas que considerassem a realidade dos "professores-alunos" e dos seus respectivos contextos de atuação profissional. Porém desta vez a figura do "professor" apareceu como o problema, por excelência, em sala de aula. Esteve evidente a desmotivação em relação à formação proposta pelo PROESP e, mesmo o descuido em relação ao tema do seminário que ministrei. A escassez de tempo para que se dedicassem às aulas e uma metodologia de ensino, segundo o depoimento dos alunos, inadequada à realidade dos "professoresalunos" seriam os detonadores desta situação.

\section{OS PROJETOS DO PPCOR}

O Projeto Tutoria era uma decorrência do Programa A Cor da Bahia da Faculdade de Filosofia e Ciências Humanas (FFCH) da UFBA. Na execução do programa de trabalho do Tutoria, um projeto para permanência na universidade, observei coerência e bastante controle entre o que foi proposto e o que se mostrou realizado. Considerando a precariedade das instalações e recursos disponíveis na Faculdade de Filosofia e Ciências Humanas da UFBA, o Programa A Cor da Bahia dispunha de uma infra-estrutura muita boa. Estas mesmas instalações e recursos - sala de computadores e estudo para os alunos; uma sala para encontros e eventos; uma terceira sala de reunião e trabalho para a coordenação; telefone, fax, TV, vídeo, ar condi- 
cionado - eram disponibilizados para os estudantes do Projeto Tutoria. Os alunos eram reunidos ao menos uma vez por semana, quando participavam de atividades programadas - filmes, palestras, apresentação de resultados de pesquisas, minicursos - voltados para complementação da formação acadêmica, mas, sobretudo para a reflexão sobre relações raciais, racismo e cultura negra no Brasil e no mundo. A propósito, na ocasião da minha visita, depois de assistirem ao filme "A Negação do Brasil", do cineasta negro Joel Zito Araújo, os estudantes, conduzidos pela coordenadora do Projeto, discutiram o filme e levantaram questões surpreendentes e maduras sobre identidade racial e racismo nos meios de comunicação. O que me pareceu um reflexo da formação que vinham recebendo no Tutoria. Além disso, os alunos recebiam orientação acadêmica, eram estimulados a participar ativamente do dia a dia da universidade e alguns deles, estudantes do curso de ciências sociais, mais maduros intelectualmente, trabalhavam como assistentes de pesquisa dos coordenadores ou de pesquisadores associados ao Programa A Cor da Bahia.

O formato institucional do Programa A Cor da Bahia - ou seja, seu caráter de núcleo de estudo sobre relações raciais e cultura negra que fomentava a presença e trânsito permanente de pesquisadores e professores universitários negros brasileiros e estrangeiros - contribuiu bastante para alcance dos objetivos fundamentais do Projeto Tutoria, quais sejam: o desenvolvimento do interesse dos estudantes pela vida e produção acadêmica e a formação de "lideranças intelectuais". Além disso, apesar de não ser um objetivo claramente apresentado no projeto original, o Tutoria pareceu ter contribuído na elaboração ou reelaboração da identidade racial dos estudantes assim como na formação de "lideranças políticas" também. Na conversa com os coordenadores, os mesmos afirmaram que, desde o início do Projeto Tutoria, observaram visíveis transformações nos alunos. Alguns se "reconverteram" racialmente. Ou seja, no processo de seleção se autoclassificavam como mestiços ou apresentaram dificuldades na autoclassificação racial e naquele momento não apenas se classificavam como "negros", mas (re) elaboravam em seus corpos e refletiam sobre esta nova identidade. Além disso, alguns alunos teriam, espontaneamente, decidido participar do movimento estudantil, introduzindo o corte racial na sua ação política.

Através da conversa e observação dos estudantes, constatei que, inclusive os mais tímidos, demonstraram uma articulação verbal e crítica rara entre estudantes universitários de semestres iniciais. Além disso, confirmaram uma mudança na compreensão da questão racial, como evidencia a 
seguinte fala: "Antes pensava que o preconceito era mais uma questão social, econômica, agora vejo que é também racial!"

Estes alunos afirmaram também que a UFBA não refletia o que eles eram. Tal realidade institucional e acadêmica, portanto, não apenas thes oprimia, mas também os reprimia como sujeitos na medida em que eram constrangidos no que diz respeito à elaboração e enunciação de discursos críticos sobre o modo como percebiam a representação social do grupo ao qual pertenciam. O Projeto Tutoria, abrigado institucionalmente no Programa A Cor da Bahia, apareceu na fala dos estudantes como um espaço de amparo emocional e psicológico - "aqui a gente se sente como um grupo racial na universidade" - , como um espaço de articulação política - "aqui, eu aprendi a articular melhor a crítica contra o racismo e a desigualdade racial"; "na universidade se disputa espaço e competência" - e por fim, como um espaço de crítica e elaboração teórica sobre questões raciais "outro dia no debate com um pesquisador branco que estuda relações raciais aqui na Bahia, eu percebi uma estranheza do "objeto negro" na sua fala"; "aqui eu estou desconstruindo conceitos".

Segundo os coordenadores, o Projeto Tutoria foi elaborado no sentido de expandir a reflexão sobre relações raciais e garantir a permanência de estudantes "negros e mestiços" não apenas nos cursos das ciências sociais e humanas, onde os negros da UFBA estão em expressivo contingente e são mais freqüentemente expostos a esta reflexão, mas também em outras áreas menos sensíveis como as ciências exatas e artes. Nestas áreas, argumentaram ser menos provável que os departamentos considerassem esta questão e associassem o desempenho dos alunos à trajetória racial. Apesar da dificuldade em sensibilizar os departamentos destas áreas, os coordenadores do Tutoria consideraram um avanço a conquista da simpatia ao menos de alguns professores, que se disponibilizaram a visitar e proferir palestras sobre temas das suas áreas de estudo. O Tutoria conseguiu também boa visibilidade na FFCH e em outros institutos da UFBA e participou ativamente do debate sobre cotas para negros e índios na universidade pública. Além disso, reclamou-se da escassez de recursos que dificultavam, por exemplo, a promoção de um curso de língua estrangeira regular para todos os bolsistas.

A proposta político-pedagógica do Projeto Tutoria de congregar estudantes advindos de áreas e institutos diferentes e conduzi-los ao estudo e reflexão sobre uma questão comum restabelece continuidades entre saberes que têm se colocado como apartados e, em graus variados, desarticula- 
dos da realidade social. Além disso, favorece a renovação destes saberes, assim como a reabertura da imaginação de uma universidade bloqueada, elitizada e objetificadora da realidade social, como bem observa José Jorge de Carvalho:

Nossa forma principal de relacionamento com a sociedade sempre foi objetificadora. Afirmo-o inclusive porque a própria disciplina com que sou identificado, a Antropologia, que em princípio alega exercitar um diálogo com as chamadas sociedades "nativas", continua trazendo seus vários "outros" para perto de nós apenas como objetos de estudo. E esta não é, na verdade, a maneira de trazê-los ao nosso meio como iguais, mas apenas de observá-los para fins científicos. A consciência dessa objetificação tem crescido tanto ultimamente entre os excluídos que, em uma discussão sobre cotas, no Rio de Janeiro em 2003, um estudante disse a um professor negro que era contra as cotas: "O senhor está com medo de que o micróbio assuma o microscópio?" (CARVALHO, 2005, p. 140).

Diferente do Projeto Tutoria, o PRUNE pretendia garantir o acesso à universidade pública. Este projeto tentava estabelecer um diferencial em sua prática político-pedagógica ao conceber uma proposta de atuação que pretendia formar o estudante não apenas para obter um bom desempenho no vestibular, mas, sobretudo, atender à suposta demanda universitária por sujeitos reflexivos, críticos e transformadores da realidade. Neste sentido, ao mesmo tempo em que trabalhava com os estudantes o conteúdo tradicional das provas do vestibular, enfatizava o debate sobre cidadania, exclusão social, racismo, relações raciais e mobilização popular. A própria formação original do projeto refletiu isso, uma vez que o PRUNE nasceu da iniciativa conjunta de educadores relacionados a um grupo cultural negro de Itabuna, o ENCANTARTE, ao movimento negro organizado nesta cidade, - Ação Negra, e a setores do movimento sindical organizado, o SINDIALIMENTAÇÃO. Além disso, trabalhava, naquela ocasião, em parceria com a prefeitura de um partido político, o PT, auto-reconhecido como revolucionário. Com exceção do SINDIALIMENTAÇÃO, que se afastou do PRUNE, todas as entidades citadas participavam da coordenação dos trabalhos.

Concluí que aquele era um projeto de acesso que, provavelmente, acabaria por se redefinir como projeto de acesso e permanência, uma vez que o seu quadro de professores era formado por estudantes universitários pobres com dificuldades de permanência na universidade. Além disso, na própria coordenação trabalhava uma estudante de graduação da Universidade Estadual de Santa Cruz (UESC) e estudantes do PRUNE. O trabalho do PRUNE fazia um decidido e prioritário corte racial, mas também de classe e 
orientação política. Ou seja, a maioria absoluta dos alunos era negra, mas encontravam-se brancos pobres também. No quadro de professores encontravam-se negros e brancos com maior ou menor grau de crítica racial, porém todos sensibilizados politicamente com uma necessidade de transformação social e revisão político-pedagógica do sistema de educação pública no Brasil. Neste sentido, percebi que havia divergências na coordenação do PRUNE em relação à necessidade e importância de que seu quadro de professores, alunos e coordenação fossem restritamente formados por negros. Pareceu-me uma questão controversa para a coordenação, mas não pude formular com clareza o nível deste debate no PRUNE, primeiro pelo pouco tempo da visita, segundo pelo fato de que uma ou outra posição não me pareceu bem amadurecida pelos coordenadores. Ou seja, na ocasião, a coordenação não avaliava devidamente até que ponto a identidade racial, por exemplo, do professor do PRUNE, acelerava ou facilitava o trabalho com os alunos.

Além dos cinco núcleos previstos no projeto original, o PRUNE se responsabilizava por outros cinco surgidos depois da parceria com a Prefeitura Municipal de Itabuna, totalizando 500 alunos "pré-universitários". Eram alunos egressos da precária escola pública. Desempregados, de famílias de baixa renda. Muitos afastados da sala de aula há vários anos, outros tantos fragilizados psicologicamente em virtude de uma sensação de fracasso continuado e no que diz respeito à formação escolar, todos sem segurança e auto-estima suficiente para enfrentar o concorrido vestibular da UESC. Além disso, em suas falas, percebi uma desconfiança e insegurança em assumir um ponto de vista diferencialista e de reparação de perdas sociais e raciais históricas. Neste sentido, me pareceram sob a influência de um contexto municipal que ainda traz um forte resíduo colonial e aristocrata, marcados pelas relações políticas, econômicas e sociais conduzidas, no passado, pelos coronéis da economia do cacau. Além disso, segundo a coordenação do PRUNE, a reitoria e boa parte dos professores, alunos brancos e negros da UESC não só eram contra, assim como sabotavam o debate e a decisão por ações afirmativas para negros.

O fundamental desafio que se colocava o PRUNE, portanto, era não só corrigir a formação escolar, mas também fazer o aluno refletir sobre a motivação das suas dificuldades de trajetória e compreender que podia ultrapassar os obstáculos através da reinserção social como sujeito de direitos, crítico e posicionado. Neste sentido, considerando a motivação e conjunção política que originou o PRUNE, parecia acertada sua concepção co- 
mo um curso "pré-universitário" para negros e excluídos (pobres, brancos pobres, mulheres ou indivíduos com idade mais avançada) que foram obrigados a renunciar ao projeto de continuar os estudos. Por outro lado, como executar um programa político-pedagógico crítico e renovador, com escassos recursos materiais, para um público diversificado, que cresceu exageradamente - cerca de 500 alunos "pré-universitários", que deveria aprender a responder às questões do vestibular, porém só atingiria tal meta desde quando orientados por uma pedagogia que considerasse específicas dificuldades cognitivas, materiais e emocionais relacionadas à raça, à classe, ao gênero à faixa etária?

Até aquele momento, o PRUNE, de fato, não havia sistematizado devidamente um projeto político-pedagógico de acordo à sua própria concepção. Diria que o esboçou, logo no dia a dia este esboço aparecia incipiente e controverso. A orientação política de "esquerda" dos formuladores do projeto, por um lado, era um suporte ao projeto, porém se mostrou um empecilho para avançar a crítica a pedagogia tradicional que despreza a necessária valorização e afirmação da diferença racial e étnica. Ou seja, esta orientação política à esquerda do PRUNE evidenciava o limite que o discurso dos movimentos anti-racistas há muito articulam no Brasil: não basta incluir combatendo a desigualdade de classes ou de gênero, pois, uma vez que o mercado capitalista no Brasil não absorve toda a mão de obra disponível, hierarquiza a incorporação através da diferenciação racial, reforçando assim as desigualdades raciais.

A incipiência e controvérsia entre o que foi formulado e que era executado pelo PRUNE se evidenciou na conversa com alguns professores. Estes reclamaram da falta de recursos, da falta de material didático, do salário baixo, da necessidade de "improvisar do nada", da enorme deficiência de formação dos alunos. Por outro lado, apontaram que se percebiam redefinindo-se como sujeitos e transformando posicionamentos anteriores em relação à questão racial. Questionaram também a não existência de um material político-pedagógico que orientasse melhor o professor em sala de aula. Ou seja, dificuldades comuns eram encaminhadas individualmente. Percebi que, brancos ou negros, os professores não estavam suficientemente capacitados para enfrentar as dificuldades mais comuns e aplicar as diretrizes do PRUNE e do PPCor. Ocorria também que algumas iniciativas da coordenação no sentido de capacitar melhor os professores - palestras, reuniões pedagógicas, atividades extraclasses - sofriam do pouco interesse e participação dos mesmos. Daí que na conversa com professores e alunos apareceu, reiteradamente, o dilema: reeducava-se para a vida e para 
uma futura participação crítica na universidade, reforçava-se a auto-estima de estudantes cotidianamente abandonados e maltratados, porém o conteúdo programático do vestibular corria o risco de ser negligenciado, não ser cumprido ou não ser absorvido pelo aluno de formação precária. E viceversa. A não solução de tal dilema implicava em menor índice de aprovação no vestibular e na geração de frustrações, afinal o objetivo fundamental dos estudantes era o acesso à universidade que os exclui. $\mathrm{O}$ objetivo do PRUNE era aprovar vestibulandos críticos e autoconscientes.

O Projeto Auta de Souza em Olinda-PE trabalhava com um programa político-pedagógico muito próximo àquele elaborado pelo PRUNE. Do mesmo modo, era bastante sensível à especificidade da trajetória de abandono e exclusão daqueles para os quais se dirigia, priorizando também um trabalho de elaboração ou reelaboração reflexiva da identidade racial e étnica dos estudantes. Coincidia ainda com o PRUNE no fato de que não possuía sede própria nem dispunha de um espaço com infra-estrutura ideal para aulas e atividades extras. Do mesmo modo, recusava o modelo pedagógico dos cursos pré-vestibulares do mercado, assim como enfrentava dificuldades em encontrar apoio da comunidade universitária da UFPE. Além disso, também enfrentava problemas de evasão de alunos que em algum momento não possuíam recursos para se deslocar até a sala de aula, eram pressionados pela família para que se alocassem em alguma atividade remunerada ou, simplesmente, não se identificavam com a concepção político-pedagógica do Projeto Auta de Souza. Daí resultava o Auta de Souza trabalhar com uma minoria de alunos permanentes na universidade e uma maioria de alunos de acesso flutuantes.

Por outro lado, distinguia-se o Auta de Souza pelo fato de trabalhar com um grupo de alunos muitíssimo mais reduzido (cerca de 20 estudantes), porém com um programa político-pedagógico melhor articulado e com maior grau de sistematicidade. Deste modo, o alcance social quantitativo do trabalho do Auta de Souza era menor do que o do PRUNE, porém o alcance qualitativo era maior. Além disso, na medida em que coordenadores e educadores tinham um contato mais direto com os estudantes, atuavam melhor como referências políticas e intelectuais, exerciam maior controle e vigilância sobre tendências ao individualismo, ao autoritarismo, falta de compromisso e manifestação de formas de preconceito e discriminação que interceptam as representações racistas sobre os negros, por exemplo, a objetificação do corpo negro ou a maior estigmatização do negro homossexual. 
A propósito, trago um dado de observação valioso. Na conversa com os estudantes, reconheci dois dos estudantes do Auta de Souza, como homossexuais. No grupo, pareceram constituir um vínculo relacionado à identidade racial e entre eles também relacionado à sexualidade. Na conversa com o grupo, falei sobre política de diferença e, propositalmente, afirmei também a diferença de orientação sexual. Mais tarde, os coordenadores me relataram que desde o início das atividades do projeto, na medida em que se foi criando um espaço para que todos tivessem a liberdade de se expressar e afirmar experiências pessoais de exclusão, estes jovens, cada vez mais visivelmente incomodados, reivindicaram do grupo a oportunidade para falar sobre sua condição homossexual. Na avaliação dos coordenadores, isto fortaleceu no grupo a capacidade de aceitação da diferença do "outro", facilitou a compreensão crítica do preconceito e discriminação racial, assim como reforçou a solidariedade de uns em relação a outros.

Outro dado valioso desta conversa foi encontrar uma estudante que podia ser socialmente classificada como branca, mas que, depois do trabaIho no Auta de Souza, se reclassificou como negra. Interessante em relação a esta estudante é que ela tem clareza de que é socialmente vista como branca, que é tratada como tal, que pode agir como tal e ser privilegiada por esta razão em relação à maioria dos colegas, porém em sua consciência política e racial se afirma como negra. Contou-me ser filha de um pai negro, o qual foi ensinada a odiar, e agora sabe que odiava o pai porque ele era negro. $\mathrm{O}$ fato de contar com um trabalho de orientação psicológica - uma das coordenadoras do Auta de Souza é uma psicóloga negra - municiava o enfrentamento destas questões e demandas cotidianas que eram também, a meu ver, de ordem psicológica e/ou psicanalítica e precisavam ser tratadas também como tais. $O$ caso desta estudante nos mostra, por um lado, o aspecto relacional, histórico e transitivo das identidades (HALL, 1994), assim como evidencia o fato de que no Brasil a classificação e identificação racial estão relacionadas ao modo como o indivíduo se vê ou é visto, mas também a uma combinação entre o que Thales de Azevedo (1996) compreendeu como "status atribuído" pelo nascimento e fenotipia e "status adquirido" através de posições de prestígio social, letramento. Ou seja, existem negros no Brasil que podem não ser vítimas ou experimentar uma atenuação do racismo e da desigualdade racial ainda que se apresentem como negros.

Em sala de aula, o Auta de Souza trabalhava com o que chamava de "módulos de vivência". Tais módulos eram menos uma disciplina formal e 
mais conteúdos geradores de conhecimento úteis para o vestibular e para a vida social:

Módulo I: Auto-estima e Pertencimento Étnico-racial. Discutia orientação profissional, auto-estima e estereótipos do negro.

Módulo II: Reflexão Social e Histórica. Neste caso, as disciplinas História do Brasil e Geografia Humana eram trabalhadas através de reflexão sobre a conjuntura atual brasileira.

Módulo III: Poder, Controle Social e Participação Cidadã. Tais temáticas suscitavam conteúdos de História do Brasil e Geografia Humana, História Geral, Literatura, Redação e Sociologia.

Módulo IV: Ciência do Cotidiano. Esta temática convocava conteúdos das disciplinas Biologia, Química e Lógica.

Deste modo, o Projeto Auta de Souza investia na formação de sujeitos posicionados e críticos, mas também os preparava para estudar melhor. Ocorre, entretanto, que o conteúdo programático do vestibular acabava não sendo esgotado por falta de recursos que possibilitassem contratar mais professores, remunerá-los melhor, oferecer mais horas de aulas ou disponibilizar instrumentos didáticos mais adequados. Diante disso, o Auta de Souza estimulava os estudantes a buscarem alternativas para compensação de suas deficiências de formação escolar, certo de que os processos de aprendizado de conteúdos formais destes estudantes tendiam a ser facilitados e acelerados em conseqüência do trabalho que realizavam no Auta.

Apesar disso, permanecia certa frustração e inquietação nos alunos quando percebiam que todo o programa do vestibular não era abordado e que de fato era pouco prático e oneroso compensar isoladamente suas deficiências de formação lendo, ouvindo e vendo informações úteis para o vestibular. Acredito que seria fundamental para o Auta de Souza sistematizar ainda mais sua proposta, formulá-la claramente aos estudantes e, com mais recursos, aumentar a carga horária e compreender mais objetivamente sua proposta em seu caráter experimental e propositivo para uma política de ações afirmativas e reconstrução do sistema de educação pública no Brasil.

O Projeto Casa do Padre Melotto foi o último que visitei, foi também aquele que mais me surpreendeu, do mesmo modo que me deixou confuso em relação à política de financiamento do PPCor. Por um lado, era o projeto com a melhor infra-estrutura, com a mais articulada rede de financiamentos e apoios nacionais e internacionais facilitados pelo aval e legitimidade conferidos pela Igreja Católica. Enquanto os outros projetos dispunham de 
um espaço com algumas salas ou tomavam de empréstimo espaços precários da Prefeitura Municipal ou do Estado, o Casa do Padre Melotto dispunha de um prédio inteiro muito bem conservado e infra-estruturado. Neste, encontrei várias salas de estudos, biblioteca precária, mas acessível, salão para eventos e aulas de teatro, sala de coordenação com computador, telefone, fax, armários, mesa, cadeiras, xerox. Além disso, uma sala com vários computadores em rede para utilização dos alunos, um grande refeitório e área aberta.

O projeto beneficiava diretamente cerca de 80 alunos de duas escolas de nível médio em Olinda-PE, acompanhados do primeiro ao terceiro ano de estudos. Também se definia como um projeto de acesso à universidade pública. Embora tivesse um importante trabalho de orientação psicológica, desenvolvesse nos estudantes senso de solidariedade, companheirismo, responsabilidade social, estímulo à expressão artística e cultural através de aulas de teatro e criação literária, o Casa do Padre Melotto, diferente dos outros projetos de acesso, priorizava reforço e complementação do conteúdo formal transmitido na escola pública. Ou seja, apesar de não ser uma instituição de ensino secundário formal, reconhecida pelo MEC ou pela secretaria estadual de educação, o projeto funcionava como uma escola de tendência conteudística. Todos os dias, os estudantes passavam todo um turno na sede do projeto participando de atividades programadas que incluíam aulas das disciplinas formais - matemática, português, história, etc. - e atividades extraclasse. Em outro turno, se dirigiam para a escola onde estavam matriculados. Muitas vezes, num terceiro turno mais curto, ainda costumavam voltar para a sede do projeto quando participavam de curso de informática ou de outra atividade extraclasse e realizavam seus trabalhos escolares. No Casa Melotto, portanto, faziam refeições, higiene pessoal e eram treinados numa vivência comunitária e cooperativa.

Além dos professores remunerados, a equipe de funcionários do projeto era mínima. Estava reduzida ao coordenador geral, um pedagogo financiado por uma instituição estrangeira e dois educadores financiados pelo projeto. A manutenção e organização do espaço, portanto, era garantida pela participação obrigatória de todos os alunos, na divisão, coordenação e execução de tarefas. Deste modo, os estudantes desenvolviam também a capacidade de liderar ou protagonizar ações uma vez que todos revezavam trabalhos de coordenação e execução de tarefas.

O impacto do Projeto Casa do Padre Melotto sobre os estudantes era visível na empolgação e interesse que demonstravam com as atividades da Casa assim como no melhor desempenho nos estudos da escola formal. Era 
possível também identificar nos estudantes uma auto-estima elevada, assim como projetos de futuro jamais esboçados. Alguns estudantes me confessaram que "seria bom se pudessem ficar o dia inteiro no projeto" ou que "seria bom se a escola fosse como o projeto". Visitei um dos colégios Colégio Sigismundo Gonçalves - de onde os estudantes eram provenientes. Segundo a coordenação do Casa do Padre Melotto, aquele era mais organizado, tinha uma direção e orientação pedagógica mais comprometida e consistente. De qualquer modo, comparado à realidade que os estudantes encontravam na Casa Melotto era uma situação bastante contrastante e desoladora.

O prédio do Sigismundo Gonçalves estava situado numa avenida bastante movimentada e barulhenta em Olinda, o que interferia na concentração de professores e alunos. Era um espaço exíguo, úmido, calorento, mal iluminado, sujo, feio e desconfortável. Além disso, apesar do esforço incomum dos diretores e orientadores pedagógicos oferecia muito menos estímulos aos estudantes. Neste contexto, os beneficiados do Casa do Padre Melotto acabavam se destacando na sala de aula em relação aos colegas que não faziam parte do projeto. O Casa do Padre Melotto funcionava, portanto, com um projeto de acesso à universidade pública e de permanência na escola pública.

O que me inquietou, deveras mente, no Casa do Padre Melotto foi o fato de que não mencionavam a questão racial. Embora boa parte dos alunos, a maioria talvez, pudesse ser classificada como negra, estes alunos foram integrados pelo critério de classe ou perfil de personalidade adequado ao regime do Casa Melotto. Questionei a coordenação a respeito disto. Confirmaram o que percebi, mas ponderaram que, ocasionalmente quando surgia algum conflito entre os alunos, motivado por preconceito e discriminação racial, aproveitavam a situação gerada pelos próprios alunos para discutir a questão.

Acontece que nem os coordenadores e muito menos os professores pareceram suficientemente capacitados para isso. Em relação aos coordenadores o fato de serem todos brancos, um deles estrangeiro, agravava a situação uma vez que, deste ponto de vista, se distanciavam da percepção de como o racismo se manifesta e atinge subjetivamente o negro assim como tendiam, desta posição racial, a pensar o racismo e desigualdade racial como uma questão menor num quadro social em que se pensa que 0 "fundamental é a questão de classe", como afirmou um dos coordenadores, ou o vínculo social genérico como "brasileiros" (ver CARVALHO, 2005). Con- 
siderando a ênfase que a coordenação do PPCor atribuía à questão racial, pareceu-me incoerente o financiamento do projeto Casa do Padre Melotto. Apesar da seriedade do trabalho que realizava, a rigor, este último projeto não tematizava ou trabalhava "a cor na educação".

\section{OS PROFESSORES-ALUNOS DO PROESP}

No livro Afirmando Direitos (2005), organizado por Nilma Lino Gomes e Aracy Alves Martins, encontramos depoimentos inusitados de professores brancos a respeito da percepção da sua branquitude em relação à negritude de alunos e alunas do Programa Ações Afirmativas na UFMG. O inusitado está no fato destes professores reconhecerem publicamente e tentarem se distanciar criticamente da privilegiada posição racial de professores brancos em sala de aula. Muitos deles confessam-se constrangidos ao reconhecerem um olhar racista e naturalizante, jamais problematizado, sobre si e sobre seus alunos negros. A propósito segue o depoimento da professora universitária Maria Cristina Soares de Gouvêa, Professora Adjunta do Departamento de Ciências Aplicadas à Educação da Fae/UFMG e participante do Programa Ações Afirmativas na UFMG.

[...] Meu lugar social, os valores pelos quais fui formada e as referências identitárias me situaram num universo cultural identificado com os modelos dominantes. [...] Tentando resgatar minha vivência, fica claro como o racismo sempre foi tomado como uma categoria estranha ou inadequada para pensar as relações raciais no Brasil, para os grupos brancos. Não somos como os brancos norte-americanos, sul-africanos ou alemães; e a afirmação dessa diferença sempre assumiu um sinal de positividade. Se em nossa história não enforcamos negros, não construímos um aparato legal segregacionista, nem políticas de eliminação de outras raças, não somos racistas, como associamos a esses outros povos. [...] No caso das camadas brancas médias, o negro, sujeito concreto, constituía um personagem ausente dos espaços de sociabilidade, habitante das sombras, mudo, permanentemente acompanhado de bandejas, vasilhas, foices, panelas, vassouras, qualquer instrumento de trabalho braçal. Era a partir do lugar de trabalhador desqualificado e ignorante que esse sujeito era situado na cena social urbana brasileira para os grupos brancos de classe média. Ou, na contraface dessa representação excludente, como associado à marginalidade e ao perigo (GOUVÊA, 2005, p. 182; 183).

Em relação aos "professores-alunos" do PROESP/UNEB com os quais trabalhei em março de 2006, no Campus II da UNEB, o primeiro estranhamento notado foi o desconforto dos professores-alunos quanto à afirmação da minha condição de professor negro, atento às representações racializa- 
das sobre seus alunos e sobre si mesmos. Este desconforto se manifestou através de olhares e gestos que evidenciavam uma dificuldade em falar e discutir um tema considerado espinhoso e tabu por estes professoresalunos. Por conta disso, iniciei a discussão buscando informações sobre o cotidiano da escola e condições de trabalho. Os professores-alunos me informaram que atuam em condições bastante insatisfatórias. A maioria trabalha em turnos seguidos ministrando, inclusive, disciplinas para as quais não foram habilitados. Há casos de professores com formação em história que completam sua carga horária ministrando aulas de ciências ou mesmo de educação física. O único recurso didático, nem sempre disponível para todos, é o livro didático que se distancia da realidade social, cultural e, muito grave, racial do professor e do aluno.

Os professores observaram também que, por um lado, há, nos últimos tempos, reincidentes discussões sobre as dificuldades do aluno em permanecer na escola e apreender o conhecimento transmitido. Do mesmo modo, há uma "cobrança" para que o professor busque soluções criativas e adequadas para combater estas dificuldades. Por outro lado, afirmaram, não haveria o mesmo interesse pela valorização do professor. Os salários são baixos; a carga horária é excessiva; as salas são superlotadas, dificilmente podem dispensar atenção especial aos alunos mais problemáticos. A sobrecarga de trabalho dificulta ao professor pesquisar, atualizar o conhecimento, introduzir conteúdos e metodologia de ensino mais adequado à realidade do aluno e se recompor psicologicamente. Argumentaram ainda que, em sala, o professor é obrigado a atuar também como pai, mãe, psicólogo e não tem apoio da escola para isto, inclusive psicológico. Ouvi que na escola "o professor, como educador, está sempre só" e desprotegido em relação ao autoritarismo de diretores de escolas e secretários de educação uma vez que há uma forte vinculação das diretrizes da educação aos interesses políticos dos municípios e do Estado. Além disso, mesmo quando buscavam a requalificação em programas como o PROESP, consideravam o resultado pouco estimulante. "Muitas vezes os professores exigem muito trabalho fora da sala e não há tempo vago para ler muito ou preparar devidamente as atividades". Afirmaram que o ideal era que tivessem, ao menos, 20h disponibilizadas para cursos de formação e requalificação e as atividades levassem em consideração a realidade que vivenciam. "No fundo, a gente finge que aprende. O professor finge que ensina", ou seja, reproduziam o contexto da sala de aula em que atuavam como professores. 
Em seguida, estimulei os "professores-alunos" a descreverem a sala de aula e seus alunos. Os alunos apareceram como "pobres", "mergulhados em conflitos domésticos que chegam até a sala", "desestimulados", "agressivos", "carentes de tudo". Quanto à identidade racial e étnica nada se mencionou até que perguntasse sobre esta questão. A partir daí, a primeira resposta foi que os alunos eram "misturados" ou classificáveis como "pele clara", "tchu tchu", "sarará", "brancos que não eram brancos mesmo", "afro-descendentes". Percebi também que os professores confundem descendência com identidade racial. Ou seja, na dúvida ou constrangidos em classificar seus alunos ou a si mesmos como brancos, negros, amarelos ou "misturados" optam pela classificação mais em evidência atualmente na UNEB e na mídia, aparentemente aparadora de arestas raciais: "afrodescendente". Desta forma, por um lado, excluíam a possibilidade da classificação "branco-descendente" ou "índio-descendente" o que contraria o discurso da democracia racial ou da meta-raça brasileira formulado por Gilberto Freyre (1989) e presente no senso comum universitário. Por outro lado, por omissão, apontavam também para uma "branco-descendência" ou "índio-descendência" o que reafirma o discurso da brasilidade mestiça, do vínculo genérico como "brasileiro" e esvazia o discurso de diferenciação racial. Perguntei aos "professores-alunos", então, se a descrição dos seus alunos era equivalente a que fariam de si mesmos. Responderam afirmativamente. Em seguida, os conduzi a apontar marcas fenotípicas dos seus alunos. Os "misturados" /"afro-descendentes"/"tchu tchu"/"sararás" foram descritos como portadores de "nariz feio", "cabeça chata", "lábios grossos e sensuais", "cabelo bombril ou assolan", "cabelo duro", "pé chato", "dedos curtos", "bunda grande, empinada e dura", "neguinho insuportável".

Os "professores-alunos" distinguiram os alunos e a si mesmos através de marcas fenotípicas degradantes e não exatamente através de uma classificação racial. Por outro lado, as marcas fenotípicas apareceram como metáforas, se é possível falar assim, das raças uma vez que dispunham de outro modo o sujeito num dos pontos da hierarquia das raças. As marcas que remetem ao negro o descrevem de modo pejorativo, sexualizado ou exotizado. Em seguida, foi solicitado que a turma se dividisse em pequenos grupos e realizasse a leitura dirigida do texto "O educador, a educação e a construção de uma auto-estima positiva no educando negro" de Jeruse Romão (2001).

Após a leitura, a discussão rendeu pouco. Insisti e a turma se manifestou. Reagiram sem muito entusiasmo ao texto quando perceberam que a autora propunha uma ação transformadora no que diz respeito ao trata- 
mento da questão racial na escola, desconsiderando as dificuldades diárias que Ihes conduzem a letargia e sensação de impotência. Ou seja, para aqueles "professores-alunos" a autora propõe uma transformação supondo condições de trabalho e atuação que não são as reais e cotidianas. Em seguida, exibi o filme norte-americano "Coach Carter - Treino para a vida", de Thomas Carte, que narra as dificuldades de um professor de basquete em disciplinar jovens majoritariamente negros, agressivos, pobres, sem perspectivas e advindos de contexto familiar desestruturado. Até o final do filme, a sala estava quase vazia. Muitos se retiraram sob o argumento que moravam em outras cidades e acabariam perdendo o horário do ônibus.

No terceiro momento do seminário temático, iniciei as atividades comentando o filme exibido na sessão anterior e apontando quais aspectos da narrativa do filme eram úteis para ampliar a compreensão e reflexão sobre a temática do seminário. Aqueles que assistiram ao filme até o final, fizeram observações sobre a dificuldade do professor de basquete em disciplinar os jovens comparando às suas próprias dificuldades. Não perceberam, entretanto, que o filme problematizava também a idéia de que os negros são naturalmente designados para atividades que acionam o corpo, a força física. Apontei então para este aspecto como uma atitude racializada. Em seguida, evoquei o texto de Jeruse Romão, trabalhado na aula anterior. Isto porque no filme e na sala de aula dos "professores-alunos" o aluno indisciplinado apareceu como problema e o aluno quieto, disciplinado, como, inicialmente, o desejável. Romão observa que o aluno disciplinado muitas vezes é o aluno reprimido e reativo ao controle que o professor exerce sobre formas de expressão e relação social pertinentes a contextos culturais negros, aparentemente avessos e negados pela pedagogia da sala de aula.

Depois disso, novamente a turma foi dividida em grupos e solicitouse a leitura dirigida do texto "Alguns termos e conceitos presentes no debate sobre relações raciais no Brasil: uma breve discussão", de Nilma Lino Gomes (2005). Foi a ocasião para retomar as falas dos professores desde a primeira sessão e revelar o caráter equivocado e a conotação racista presente no modo como representam e se relacionam com seus alunos. Através do texto lido, esclareceu-se o sentido de conceitos como "afrodescendência"; "identidade"; "identidade negra"; "raça"; "etnia"; "racismo"; "etnocentrismo"; "preconceito racial"; "discriminação racial"; "democracia racial". Este foi o momento em que os "professores-alunos" alteraram a postura e a atitude em sala de aula. Mais interessados, perceberam- 
se como alunos diante do professor negro e homossexual e como professores racistas diante de seus alunos. Perceberam também como o material didático-pedagógico para trabalhar a questão da diferença e do racismo poderia ser aproveitado de suas frases, suas atitudes e das situações recorrentes em sala de aula, por eles mesmos citadas. Entretanto, isto demandaria um outro esforço impossível naquela ocasião.

\section{CONSIDERAÇÕES FINAIS}

Acredito que, se por um lado, é de fundamental importância a existência de iniciativas individuais, de agentes financiadores e Organizações Não Governamentais no sentido de atacar a indiferenciação étnica e racial em sala de aula e a incompreensão da importância do desenvolvimento de práticas didático-pedagógicas que valorizem as alteridades excluídas, pouco se avança uma vez que o Estado e suas instituições, que se definem como democráticas, igualitárias e universalistas, não venham a corrigir problemas estruturais graves sobre os quais devem assumir responsabilidade prioritária. Logo, é importante que os articuladores e coordenadores dos projetos se esforcem em delimitar de maneira mais realista suas pretensões e metas e exijam das instituições a responsabilidade que lhes cabe. Por exemplo, considerei pouco sensato que o projeto PRUNE trabalhasse naquela ocasião com o dobro de núcleos previstos (10) e com cerca de 500 estudantes, contando com um apoio periférico da Prefeitura Municipal de Itabuna. Deste modo, como foi o ocorrido, perde-se o controle do processo e os resultados tendem a se expressar num desequilíbrio entre quantidade e qualidade dos estudantes atingidos. Ou seja, acredito ser preferível um menor número de estudantes atingidos e aprovados no vestibular, porém estudantes mais qualificados no que diz respeito ao domínio do conteúdo disciplinar formal, ao exercício de cidadania, à crítica étnica e racial e à intervenção política na universidade pública, visto que as demandas são de grande monta e os recursos materiais e humanos são sempre insuficientes. Quanto aos programas de conteúdos oferecidos pelas instituições voltadas para a garantia de acesso à universidade pública é preciso equilibrar melhor a relação entre os conteúdos exigidos pelo vestibular e os conteúdos orientadores de uma necessária crítica social. Ou seja, se não há perspectiva das universidades públicas, em curto prazo, revisarem o método de avaliação de competências e seleção de futuros graduandos, as instituições fomentadoras do acesso de negros e carentes ao sistema público de ensino superior devem formar para a crítica social inovadora, mas devem sobretudo qualificar os

52 Número temático: Literatura, cultura e memória negra. A Cor das Letras - UEFS, n. 12, 2011 
alunos para responder às questões do vestibular e dominar ferramentas fundamentais do universo acadêmico como a escrita, o raciocínio lógico ou o pensamento conceitual. Com isto quero lembrar que se as provas vestibulares têm um calendário fixo, de domínio público, os conteúdos tradicionais exigidos no vestibular devem ser revisados e trabalhados de acordo com este calendário. Melhor dizendo, é fundamental que as instituições fomentadoras do acesso às universidades públicas definam, mais objetivamente e comuniquem aos estudantes se a preparação ideal dos mesmos para aprovação no vestibular pode ocorrer em seis meses, em um ou dois anos. Isto pode gerar maior comprometimento, retorno dos aprovados e menos frustração nos candidatos reprovados e mais real possibilidade de qualificar para o vestibular, para a permanência na universidade e para a vida pública e cidadã.

No que diz respeito à questão da permanência de estudantes negros e carentes na universidade pública, o trabalho do Projeto Tutoria do Programa A Cor da Bahia da UFBA, apesar das dificuldades de apoio institucional, da fraca colaboração de docentes, em particular dos cursos de ciências exatas, da saúde e artes, se evidenciou como uma referência. A equipe de coordenação apresentou objetivos claros, compreendidos pelos estudantes, o que ampliava a adesão e confiança dos mesmos na proposta. Além disso, o projeto trabalhava com um número relativamente pequeno de estudantes o que facilitava o acompanhamento dos mesmos. Por outro lado, é de fundamental importância que se insista e se amplie a complementação da formação também de estudantes das áreas de artes, ciências exatas e da saúde. Estes estudantes serão no futuro os técnicos que ocuparão cargos em empresas privadas ou públicas ou elaborarão políticas públicas que, diferente do que ainda ocorre hoje, poderão considerar na definição de números ou ações aspectos da realidade que são relacionados à vida de grupos sociais excluídos, como é o caso dos negros. Por fim, os órgãos ou programas de fomento devem distribuir os recursos para instituições e ações que, de fato, se adéqüem as suas diretrizes orientadoras. Por exemplo, sem desconsiderar a seriedade e impacto social do trabalho da Casa do Padre Melotto, o fato é que esta instituição realizava um trabalho que não se adequava plenamente ao que era diretriz do Programa Políticas da Cor da UERJ. Apesar disto, teve seu projeto aprovado, deslocando recursos que poderiam ser aplicados nas instituições claramente comprometidas em seus projetos com o combate ao racismo e desigualdades raciais. Por fim, é fundamental que os órgãos ou programas de fomento planejem de forma 
mais realista o repasse de recursos e acompanhamento da aplicação dos mesmos. Uma queixa comum das instituições contra o PPCor foi a precária comunicação e atraso no cronograma de repasse de recursos aprovados.

Em relação a programas de requalificação de professores do ensino básico, considero improdutivo, mesmo ineficaz, desconsiderar em tais programas as demandas dos professores, fora e dentro da sala de aula, ou elaborar conteúdos programáticos e metodologias de ensino alheias às condições de trabalho em sala e fora da sala dos mesmos. Muitas vezes, este professor até tem o desejo de mudar, mas se sente tolhido porque, na prática, não há condições para reaprender, para mudar ou se tem à disposição um instrumental teórico e metodológico ineficaz diante das dificuldades que enfrenta no dia a dia. Ou seja, a UNEB ou qualquer outra universidade pública não deveria se responsabilizar pela execução de programas de requalificação de professores que já atuam no ensino básico, caso o Estado não garanta ou favoreça condições mínimas de aprendizado. Pouco pode aprender, porque pouco pode estudar e processar o que é transmitido, um professor que trabalha quarenta horas em sala de aula e tem aulas em um terceiro turno, que venha a ter redução de salário, caso solicite diminuição de sua carga horária para estudar ou tenha dificuldade de acesso ao local de estudo. Neste caso, as universidades poderiam propor ao Estado que executasse programas de requalificação equivalentes àqueles existentes nas universidades públicas quando se trata da requalificação dos professores universitários. Além disso, as universidades públicas deveriam exigir do Estado contrapartida em contratação de pessoal extraordinário, aquisição de equipamentos e remuneração mais justa aos professores solicitados a requalificar aqueles que já atuam como docentes no ensino básico.

\section{REFERÊNCIAS}

AZEVEDO, Thales. As elites de cor numa cidade brasileira. Um estudo de Ascensão Social \& Classes Sociais e Grupos de Prestígio. Salvador: EDUFBA/EGBA, 1996.

CARVALHO, José Jorge de. A extensão e os saberes não-ocidentais. In: Idem. Inclusão étnica e racial no Brasil. A questão das cotas no ensino superior. São Paulo: Attar Editorial, 2005, p. 139-165.

CARVALHO, José Jorge. Uma aliança negro-branca-indígena pela inclusão étnica e racial. In: Idem. Inclusão étnica e racial no Brasil. A questão das cotas no ensino superior. São Paulo: Attar Editorial, 2005, p. 109-138.

CRUZ, Mariléia dos Santos. Uma abordagem sobre a história da educação dos negros. In: ROMÃO, Jeruse. (Org.). História da educação do negro e outras histórias. Brasília: Ministério da Educação/SECAD, 2005, p. 21-33.

54 Número temático: Literatura, cultura e memória negra. A Cor das Letras - UEFS, n. 12, 2011 
FREYRE, Gilberto. Casa-grande \& senzala. Rio de Janeiro: Record, 1989.

GOUVÊA, Maria Cristina Soares de. Ser branco no Brasil. In: GOMES, Nilma Lino; MARTINS, Aracy Alves. (Org.). Afirmando direitos. Acesso e permanência de jovens negros na universidade. Belo Horizonte: Autêntica, 2004, p. 181-188.

GOMES, Nilma Lino. Alguns termos e conceitos presentes no debate sobre relações raciais no Brasil: uma breve discussão. In: SANTOS, Sales Augusto dos. (Org.). Educação anti-racista: caminhos abertos pela Lei Federal no 10.639/03. Brasília: MEC/SECAD, 2005, p. 39-62.

HALL, Stuart. Identidade cultural e diáspora. Revista do Patrimônio Histórico e Artístico Nacional, n. 24, p. 68-75, 1996.

ROMÃO, Jeruse. O educador, a educação e a construção de uma auto-estima positiva no educando negro. In: CAVALLEIRO, Eliane. (Org.). Racismo e anti-racismo na educação: repensando nossa escola. São Paulo: Summus, 2001, p. 10-38. 
